\title{
Implantation failures and suboptimal positions of gravitational valves - with massive impact on shunt dysfunction Barbara Vienenkötter*, Andreas Unterberg and Alfred Aschoff
}

\author{
Address: Department of Neurosurgery, University of Heidelberg, Im Neuenheimer Feld 400, 69120 Heidelberg, Germany \\ Email: Barbara Vienenkötter* - Barbara.vienenkoetter@med.uni-heidelberg.de \\ * Corresponding author
}

from 53rd Annual Meeting of the Society for Research into Hydrocephalus and Spina Bifida Belfast, UK. 24-27 June 2009

Published: 27 November 2009

Cerebrospinal Fluid Research 2009, 6(Suppl 2):S20 doi:10.1186/I743-8454-6-S2-S20

This abstract is available from: http://www.cerebrospinalfluidresearch.com/content/6/S2/S20

(C) 2009 Vienenkötter et al; licensee BioMed Central Ltd.

\section{Background}

The function of gravitational (g)-valves is strictly dependent on the angle of verticalization. For even minor axisdeviations have a significant impact on the functional pressure, a strict orientation parallel to the longitudinal body axis is important. Despite the decisive role only $1 /$ 166 g-valve-papers (incl. running studies) investigated systematically g-valve-deviations (= failure angles) to the body axis. Furthermore, the more frequent implantation site on the lateral head yet has not been compared to the thoracal site.

\section{Materials and methods}

Each 50 consecutive g-valve patients with retroauricular and thoracal implanted gravitational devices were randomly extracted from our medical records of about $650 \mathrm{~g}$ valve-implanted patients. On scout-scans/x-rays the deviations to the body axis were measured. The impact on gvalve-function and additionally the effect of a head elevation of 30 degrees were calculated.

\section{Results}

Only $22 \%$ of retroauricular vs. $28 \%$ of thoracal implantated devices were correctly placed $(<10$ degree). Valves placed on the head showed anteversion in $84 \%$ and retroversion in $16 \%$. The mean deviation was 21 degrees implying a valve-offset of $72(126) \mathrm{mm} \mathrm{H}_{2} \mathrm{O}$ in a 200 (350) $\mathrm{mm} \mathrm{H}_{2} \mathrm{O}$-g-valve, the maximum was 43 degrees (valve-offset: 136 (239) $\mathrm{mm} \mathrm{H}_{2} \mathrm{O}$ ). A nocturnal head elevation of 30 degrees may result in a mean valve-offset of
156 (272) $\mathrm{mm} \mathrm{H}_{2} \mathrm{O}$ calculated with the mean deviation angle and 191 (335) $\mathrm{mm} \mathrm{H}_{2} \mathrm{O}$ in the worst case. In the thoracal position the mean counted 10 degrees in lateral and 16 degrees in anteroposterior direction, implying a valve-offset of 55 (96) $\mathrm{mm} \mathrm{H}_{2} \mathrm{O}$ in 200 (350) $\mathrm{mm} \mathrm{H}_{2} \mathrm{O}$ valve. Maximal deviation was 52 degrees resulting in valve-offset of 158 (276) $\mathrm{mm} \mathrm{H}_{2} \mathrm{O}$.

\section{Conclusion}

Position failures are common in our series and may declare malfunction of g-valves. The thoracal implantation site is clearly superior to the head position and should therefore be preferred in adults. 